\title{
Comparison of intrathecal ropivacaine-fentanyl and bupivacaine-fentanyl in transurethral resection of the prostate of the benign prostatic hyperplasia surgeries
}

Quach Truong Nguyen ${ }^{1}$, Nguyen Hung Hoa ${ }^{2 *}$ and Nguyen Van Chinh ${ }^{3}$

*Correspondence: hunghoa86@ump.edu.vn

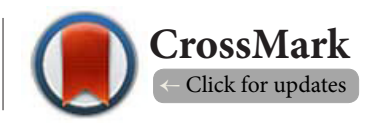

${ }^{1} \mathrm{MD}$, Binh Dan Hospital, HoChiMinh city, Vietnam.

${ }^{2}$ Ph.D., Department of Nurse Anesthetist, HoChiMinh University of Medicine and Pharmacy, Vietnam.

${ }^{3}$ Associate Professor, Department of Nurse Anesthetist, HoChiMinh University of Medicine and Pharmacy, Vietnam.

\begin{abstract}
Background: Ropivacaine has a clinical profile similar to bupivacaine with less toxic effects on the central nervous system and the cardiovascular system. Moreover, Ropivacaine may have a shorter time to recover motor function compared with bupivacaine. Therefore, Ropivacaine may be an appropriate option in spinal anesthesia for transurethral resection of the prostate.

Objectives: This paper compared the anesthetic efficacy and the adverse effects of intrathecal ropivacaine plus fentanyl with bupivacaine plus fentanyl.

Patients and methods: One hundred and sixty patients of ASA I - III, 55-80 years scheduled for transurethral resection of prostate under spinal anesthesia. A single-blinded, randomized clinical trial. Patients were randomized into two equal groups, RF group: Ropivacaine $0.5 \% 7.5 \mathrm{mg}$ plus fentanyl $20 \mathrm{mcg}$ and BF group: bupivacaine $0.5 \% 5 \mathrm{mg}$ plus fentanyl $20 \mathrm{mcg}$.

$\underline{\text { Results: }}$ the onset time of sensory block at T10 and motor block were comparable. The RF group had a shorter duration of sensory block at $\mathrm{T} 10$ of $108.1 \pm 19.9 \mathrm{~min}$ and $120.3 \pm 17.1 \mathrm{~min}$ for the BF group $(\mathrm{p}<0.0001)$. The highest sensory level achieved was comparable from T10 to T6 dermatome. The duration of the motor block in the RF group $(59.5 \pm 14.9 \mathrm{~min})$ was shorter than that in the BF group (76.9 $\pm 18.3 \mathrm{~min})$ $(\mathrm{p}<0.0001)$. Motor Bromage scale $\mathrm{O}$ in the RF group was more significant than in the BF group $(58.7 \%$ versus $41.3 \%$ ). The effective rate of spinal anesthesia in the $\mathrm{RF}$ group and $\mathrm{BF}$ group was $96.2 \%$ and $97.5 \%$. No statistical difference was found regard to adverse effects between the groups.

Conclusion: In spinal anesthesia for transurethral resection of the prostate, the RF group provided similar anesthetic efficacy and adverse effects but less motor block than the BF group.
\end{abstract}

Keywords: Intrathecal, transurethral resection of the prostate, Ropivacaine

\section{Introduction}

The prostate is a small gland in the pelvis only found in men. It has located between the penis and bladder and surrounds the urethra (the tube that carries urine from the bladder to the penis). Benign prostatic hyperplasia (BPH) is a benign tumor of the prostate in men, often occurring in the elderly. In the European and American countries, transurethral resection of the prostate (TURP) happened for $90 \%$ of cases of benign prostatic hyperplasia and is considered the "gold standard" [1]. Transurethral resection of the prostate (TURP) is a surgical procedure that involves cutting away a prostate section. Anesthesia methods for TURP include spinal anesthesia, general anesthesia, and local anesthesia. According to Mebust et al. (2002), the rate of spinal anesthesia is up to $79 \%$ in the United States [2]. In Vietnam, the rate of spinal anesthesia for TURP is $92.3 \%$ [3].

Bupivacaine is a widely used anesthetic, but it has a long motor block time and is toxic to the cardiovascular and nervous systems. Ropivacaine is an ammino-amide anesthetic, a new generation anesthetic, with properties similar to bupivacaine 
but safer than bupivacaine due to decreased toxicity on the heart and central nervous system [4]. In addition, one advantage of Ropivacaine is that this anesthetic has an earlier motor recovery time than bupivacaine due to its low-fat solubility [5]. From the above advantages, Ropivacaine may be an appropriate choice in spinal anesthesia of elderly $\mathrm{BPH}$ patients. Therefore, we researched to evaluate the effect of spinal anesthesia by intrathecal ropivacaine plus fentanyl in the transurethral resection of the prostate.

\section{Methodology}

\section{Study Design}

This study utilized a clinical trial with a single-blind. Patients were randomized into two groups.

\section{Sample}

A sample size of 160 patients of the American Society of Anesthesiologists grades I and III, aged between 55 and 80, scheduled for transurethral resection of the prostate surgeries under spinal anesthesia.

\section{Inclusion Criteria}

1. Adult patients aged between $55-80$ years,

2. American Society of Anesthesiologists (ASA) grade 1,2 and three physical status,

3. Scheduled for elective surgery under spinal anesthesia,

4. No history of allergy or sensitivity to any of the studied local anesthetics.

\section{Exclusion criteria}

1. Patients with significant cardiovascular disease, Hypertension, renal failure, hepatic dysfunction, Diabetes, and chronic pulmonary disease.

2. Neuromuscular disorder,

3. Morbid obesity,

4. Bleeding disorders,

5. Infection at the local site,

6. Any patient on prolonged drug therapy,

7. Uncooperative patients.

The patients were randomly divided into two groups using a computerized randomization table.

- Group RF ( $n=80)$ : Patients proposed to undergo transurethral resection of the prostate under spinal anesthesia using Ropivacaine $0.5 \% 7.5 \mathrm{mg}$ plus fentanyl $20 \mathrm{mcg}$.

- Group BF ( $n=80)$ : Patients proposed to undergo transurethral resection of the prostate under spinal anesthesia using bupivacaine $0.5 \% 5 \mathrm{mg}$ plus fentanyl $20 \mathrm{mcg}$.

\section{Procedure}

The patient was fitted with heart rate monitoring, lead-DII electrocardiogram, non-invasive blood pressure, $\mathrm{SpO} 2$, and set up a peripheral intravenous infusion with an $18 \mathrm{G}$ needle infused with $0.9 \%$ sodium chloride. Spinal anesthesia at the intercostal space L3 - L4, the middle line with a spinal probe number 27G. Insert the syringe with a pre-drawn anesthetic attached to the needle and inject the anesthetic in 30 seconds. Give the patient oxygen 3 liters/min through the nasal tube after spinal anesthesia.

Heart rate, electrocardiogram, blood pressure, breathing rate, $\mathrm{SpO} 2$, nausea and vomiting, chills, and pruritus were recorded before anesthesia and every 2 minutes for the first 20 minutes after anesthesia, then recorded, every 5 minutes until the end of the surgery, at the recovery room to monitor every 30 minutes and every 3 hours when transferring camp until 24 hours after spinal anesthesia. Evaluate thermal sensation closure with $100 \mathrm{ml}$ sodium chloride bottle refrigerated in the refrigerator after anesthesia every 2 minutes for the first 20 minutes, at the end of the surgery, and every 10 minutes in the recovery room. Use the Bromage scale to assess motion blocking after anesthesia every 2 minutes for the first 20 minutes, at the end of the surgery, and every 10 minutes in the recovery room. Evaluate pain level using a Numerical Rating Scale (NRS) in the wake-up room every 30 minutes and every 3 hours when transferred to 24 hours after spinal anesthesia.

Hypotension is diagnosed when systolic blood pressure is decreased by more than $20 \%$ compared with baseline or systolic blood pressure $<90 \mathrm{mmHg}$. Bradycardia when the heart rate is $<50$ beats/min and respiratory failure is diagnosed when the breathing rate is less than ten beats/min or $\mathrm{SpO} 2<90 \%$.

\section{Ethical Consideration}

This research was approved by the Medical Ethics Council of the University of Medicine and Pharmacy at Ho Chi Minh City, Vietnam, and the Medical Ethics Council of the Binh Dan Hospital.

\section{Results}

There is no significant difference between the RF and BF groups about age, height, weight, BMl, surgical duration, and ASA (Tables 1 and 2).

The difference was not statistically significant in the T10level onset duration of the sensory block and the motor block time. The mean of action time for the sensory block at the T10 level of the RF group was statistically significantly shorter than

Table 1. Sample Characteristics $(n=160)$.

\begin{tabular}{llll}
\hline Characteristics & $\begin{array}{l}\text { RF group } \\
(\mathbf{n = 8 0})\end{array}$ & $\begin{array}{l}\text { BF group } \\
(\mathbf{n = 8 0})\end{array}$ & p-value \\
\hline Age $($ year) & $68.2 \pm 6.4$ & $69.0 \pm 7.2$ & 0.56 \\
Height $(\mathrm{cm})$ & $164.4 \pm 5.5$ & $165.1 \pm 4.8$ & 0.37 \\
Weight $(\mathrm{kg})$ & $58.7 \pm 8.3$ & $60.2 \pm 8.1$ & 0.25 \\
BMI $\left(\mathrm{kg} / \mathrm{m}^{2}\right)$ & $21.7 \pm 3.0$ & $22.0 \pm 2.6$ & 0.47 \\
$\begin{array}{l}\text { Surgical Duration } \\
\text { (minute) }\end{array}$ & $38.0(28.0-50.0)$ & $36.5(30.0-52.0)$ & 0.79 \\
ASA I/II/III (\%) & $36.3 / 55.0 / 8.7$ & $40.0 / 52.5 / 7.5$ & 0.87 \\
\hline
\end{tabular}

${ }^{\star}$ RF: Ropivacaine - Fentanyl; BF: Bupivacaine - Fentanyl 
Table 2. Sensory block and motor block.

\begin{tabular}{llll}
\hline Time & $\begin{array}{l}\text { RF group } \\
(\mathbf{n = 8 0})\end{array}$ & $\begin{array}{l}\text { BF group } \\
(\mathbf{n = 8 0})\end{array}$ & p-value \\
\hline $\begin{array}{l}\text { Onset-duration of the sen- } \\
\text { sory block at T10 (minute) }\end{array}$ & $5.4 \pm 1.2$ & $5.0 \pm 1.1$ & 0.08 \\
$\begin{array}{l}\text { Action-duration of the sen- } \\
\text { sory block at T10 (minute) }\end{array}$ & $108.1 \pm 19.9$ & $120.3 \pm 17.1$ & $<0.0001$ \\
$\begin{array}{l}\text { Onset-duration of the motor } \\
\text { block (minute) }\end{array}$ & $10.6 \pm 2.9$ & $9.5 \pm 2.6$ & 0.07 \\
$\begin{array}{l}\text { Action-duration of the motor } \\
\text { block (minute) }\end{array}$ & $59.2 \pm 14.9$ & $76.9 \pm 18.3$ & $<0.0001$ \\
\hline
\end{tabular}

${ }^{\star}$ RF: Ropivacaine - Fentanyl; BF: Bupivacaine - Fentanyl

that of the BF group with the results of $108.1 \pm 19.9$ minutes and $120.3 \pm 17.1$ minutes, respectively $(p<0.0001)$. The action time for the motor block of the RF group lasted $59.5 \pm 14.9$ minutes shorter than that of the BF group with $76.9 \pm 18.3$ minutes. The difference in action time of the motor block between the two groups was statistically significant with $\mathrm{p}<0.0001$ (Table 3).

Table 3. Highest Level Sensory Block.

\begin{tabular}{llll}
\hline $\begin{array}{l}\text { Highest Level Sensory } \\
\text { Block }\end{array}$ & $\begin{array}{l}\text { RF Group } \\
\text { n (\%) }\end{array}$ & $\begin{array}{l}\text { BF Group } \\
\text { n (\%) }\end{array}$ & p-value \\
\hline T6 & $6(7.5)$ & $10(12.5)$ & \\
T7 & $9(11.3)$ & $7(8.8)$ & \\
T8 & $35(43.7)$ & $32(40)$ & 0.61 \\
T9 & $16(20)$ & $12(15)$ & \\
T10 & $14(17.5)$ & $19(23.8)$ & \\
Summary & $80(100)$ & $80(100)$ & -- \\
\hline
\end{tabular}

${ }^{\star}$ RF: Ropivacaine - Fentanyl ; BF: Bupivacaine - Fentanyl

The two groups' highest level of sensory block was above $\mathrm{T} 10$ and had a sensory block that lasted from T10 to T6. The sensory block was highest at $\mathrm{T} 8$ and the highest percentage in both groups with $43.7 \%$ of RF group and $40 \%$ of BF group. The difference in the highest level sensory block between the two groups was not statistically significant $(p=0.61)$ (Table 4).

Table 4. Highest Level Motor Block.

\begin{tabular}{llll}
\hline $\begin{array}{l}\text { Highest Level Motor } \\
\text { Block }\end{array}$ & $\begin{array}{l}\text { Nhóm RF } \\
\mathbf{n}(\%)\end{array}$ & $\begin{array}{l}\text { Nhóm BF } \\
\mathbf{n}(\%)\end{array}$ & p-value \\
\hline $\mathrm{M}_{0}$ & $47(58.7)$ & $33(41.3)$ & \\
$\mathrm{M}_{1}$ & $9(11.3)$ & $8(10)$ & \\
$\mathrm{M}_{2}$ & $12(15)$ & $27(33.7)$ & 0.04 \\
$\mathrm{M}_{3}$ & $12(15)$ & $12(15)$ & \\
Summary & $80(100)$ & $80(100)$ & -- \\
\hline
\end{tabular}

${ }^{\star}$ RF: Ropivacaine - Fentanyl ; BF: Bupivacaine Fentanyl

According to Bromage, ScaleTwo groups have the highest level of a motor block from $M_{0}$ to $M_{3}$. In particular, the motor block at level $\mathrm{M}_{0}$ is highest, and the RF group with $58.7 \%$, higher than the BF group with $41.3 \%$. The difference in the highest level of the motor block between the two groups was statistically significant ( $p=0.04$ ) (Table 5).

Table 5. Anesthetic and analgesic effects.

\begin{tabular}{llll}
\hline & RF group & BF group & p-value \\
\hline Anesthetic effect (\%) & & & \\
\hline Good & $77(96.2)$ & $78(97.5)$ & \\
Moderate & $3(3.8)$ & $2(2.5)$ & 1.00 \\
Unsuccessful & $0(0)$ & $0(0)$ & \\
$\begin{array}{l}\text { Total analgesic time } \\
\text { (minutes) }\end{array}$ & $190.9 \pm 30.6$ & $213.3 \pm 30.1$ & $<0.0001$ \\
$\begin{array}{l}\text { Effective time for analgesic } \\
\text { (minutes) }\end{array}$ & $287.7 \pm 27.5$ & $305.0 \pm 30.4$ & 0.0002 \\
\hline
\end{tabular}

${ }^{\star}$ RF: Ropivacaine - Fentanyl ; BF: Bupivacaine - Fentanyl

The good anesthetic effect of the RF group was $96.2 \%$, and the BF group was $97.5 \%$. In no case have failed to change the indifference method. Total analgesia time $(\mathrm{NRS}=0)$ and adequate analgesic time (NRS $\leq 3$ ) were shorter in the RF group than in the BF group (Table 6).

Table 6. Side effect.

\begin{tabular}{llll}
\hline Side effect & $\begin{array}{l}\text { RF group } \\
\text { n (\%) }\end{array}$ & $\begin{array}{l}\text { BF group } \\
\text { n (\%) }\end{array}$ & p-value \\
\hline Hypotension & $2(2.5)$ & $3(3.8)$ & 1 \\
Bradycardia & $3(3.8)$ & $3(3.8)$ & 1 \\
Itching & $3(3.8)$ & $4(5.0)$ & 1 \\
Cold & $6(7.5)$ & $7(8.8)$ & 0.77 \\
Nausea and Vomiting & $6(7.5)$ & $5(6.3)$ & 0.76 \\
\hline
\end{tabular}

${ }^{\star}$ RF: Ropivacaine - Fentanyl; BF: Bupivacaine - Fentanyl

There were 2 cases of hypotension in the RF group with $2.5 \%$ and the BF group with $3.8 \%$ of hypotensive patients. This difference was not statistically significant $(p=1)$. Both groups have three patients with bradycardia with $3.8 \%$, and no cases have been reported with respiratory failure in both groups. The differences in side effects of pruritus, chills, nausea, and vomiting between the two groups were not statistically significant.

\section{Discussion}

The results of our research show that the onset time of the T10 block is enough to ensure transurethral resection of the prostate (TURP) to be performed. Time for the sensory block at T10 levels of the two groups was longer than the average surgery time of TURP. Our results are similar to previous studies, which showed that the time for the sensory block at T10 levels of the bupivacaine group was longer than the ropivacaine group and the ratio of spinal anesthesia bupivacaine and Ropivacaine was 3:2. Serap Atabekoglu et al. (2007) conducted a study comparing Ropivacaine $22.5 \mathrm{mg}$ and bupivacaine 15 $\mathrm{mg}$ in geriatric patients undergoing transurethral resection with the result that time to sensory block at T10 level of ropivacaine group was shorter than that of bupivacaine group 
(119.50 \pm 46.24 minutes vs. $124.93 \pm 37.44$ minutes) [4]. A shorter time to sensory block at T10 levels of Ropivacaine compared to bupivacaine was also observed in Engin Erturk et al. (2010) when spinal anesthesia with Ropivacaine $12 \mathrm{mg}$ combined with fentanyl $20 \mathrm{mcg}$ and bupivacaine $8 \mathrm{mg}$ plus fentanyl 20 mcg ( $91 \pm 10$ minutes compared to $145 \pm 20$ minutes) [6].

The two groups' highest level of sensory block was above T10 and had a sensory block that took from T6 to T10. At this level, Ropivacaine $7.5 \mathrm{mg}$ combined with fentanyl $20 \mathrm{mcg}$ is sufficient for anesthesia response to TURP surgery. Studies of other authors showed that the highest level of the sensory block between bupivacaine and ropivacaine groups did not differ by spinal anesthesia with Ropivacaine, and the bupivacaine ratio was 3:2 [6].

Theoretically, Ropivacaine has lower fat solubility than bupivacaine, so it has less permeability to myelin-containing motor nerve fibers like Aa, leading to less motor blocking than bupivacaine. The results of our study also showed that the blocking time of the RF group was about 17.7 minutes shorter than that of the BF group. Saad A. Sheta et al. (2005) studied spinal anesthesia with bupivacaine $10 \mathrm{mg}$ and ropivacaine $15 \mathrm{mg}$ noted that Ropivacaine blocking time was 16 minutes shorter bupivacaine [7]. When combined with fentanyl, Engin Erturk et al. (2010) conducting spinal anesthesia with Ropivacaine $12 \mathrm{mg}$ plus fentanyl $20 \mathrm{mcg}$ and bupivacaine $8 \mathrm{mg}$ plus $20 \mathrm{mcg}$ showed a shorter motor blocking time of Ropivacaine compared to bupivacaine 47 minutes [6].

The results of our study show that two groups have a Bromage-based block from $M_{0}$ to $M_{3}$. In particular, the motor block at level $M_{0}$ with the highest rate in the RF group with the rate of $58.7 \%$, higher than the BF group with the rate of $41.3 \%$. Saad A. Sheta et al. (2005) spinal anesthesia with bupivacaine $10 \mathrm{mg}$ and ropivacaine $15 \mathrm{mg}$ in TURP surgery found no difference in the level of the motor block between the two groups [7]. In another study by Engin Erturk et al. (2010), the difference in the level of blocking $\mathrm{M}_{3}$ movement between the two groups of Ropivacaine $12 \mathrm{mg}$ plus fentanyl $20 \mathrm{mcg}$ and bupivacaine $8 \mathrm{mg}$ plus fentanyl $20 \mathrm{mcg}$ was statistically significant. (53.3\% vs. $80 \%$ ) [6].

Hypotension in spinal anesthesia caused by the anesthetic has spread to the level that T1-L2 will block the peripheral sympathetic nerve that affects vascular tone. At T1-T4 level will block the sympathetic nerve of the heart the resulting decrease in cardiac output and bradycardia. Critchley et al. report that approximately $69 \%$ of elderly patients require antihypertensive therapy during spinal anesthesia [8]. We noted that hypotension in the RF group with $2.5 \%$ and the BF group 3.8\%. However, in no case of severe hypotension requiring intensive resuscitation, blood pressure in these cases returned to normal after rehydration and treatment with ephedrine.

The rate of bradycardia in our study was 3.8\% in both groups. In the study of Engin Erturk et al. (2010), the author noted that the rate of bradycardia in the bupivacaine group was
$10 \%$, and the ropivacaine group was 3.3\% [6]. For the study of author Bipin J. Ganvit et al. (2013), the rate of bradycardia noted in the bupivacaine group and ropivacaine group was $3.3 \%$ and $0 \%$, respectively [9].

Oğurlu M et al. (2007) showed that when the level of the block on T6 in the elderly, the respiratory parameters will be reduced [10]. Besides, fentanyl to gene therapy may increase the risk of respiratory failure in the elderly. However, according to the study of Dsouza et al. (2018), the use of $25 \mathrm{mcg}$ fentanyl in spinal anesthesia in the elderly did not change the breathing rate, minute ventilation, expiratory $\mathrm{CO} 2$ concentration, and respiratory response to $\mathrm{CO}_{2}[11]$.

Itching is the most common adverse effect associated with opioid combination with opioids. However, this side effect is only transient, and the very different rate between studies can range from $0-100 \%$, and only $1 \%$ of patients with severe itching require treatment (10). In our study, the rates of pruritus recorded in the RF and BF groups were $3.8 \%$ and $5 \%$, respectively, and these cases were only transient and acceptable and did not require drug treatment.

The mechanism of nausea and vomiting in gene therapy may be due to direct contact of the chemical receptorstimulating regions with drugs such as opioids, hypotension associated with vasodilation, and increased systemic activity parasympathetic increases gastrointestinal motility. Nguyen Hung Hoa et al. (2021) showed that using opioid was significant in nausea and vomiting [12]. In our study, the rates of nausea and vomiting in the BF group and the RF group were $6.3 \%$ and $7.5 \%$, respectively. Engin Erturk et al. (2010) studied orthopedic trauma surgery with Ropivacaine $12 \mathrm{mg}$ with fentanyl $20 \mathrm{mcg}$ and bupivacaine $8 \mathrm{mg}$ combined with fentanyl $20 \mathrm{mcg}$. The author noted the rates of nausea and vomiting in 2 groups of times. $10 \%$ and $13.3 \%$ respectively [6].

\section{Conclusion}

In spinal anesthesia for transurethral resection of the prostate, the RF group had an emotionless effect similar to that of the BF group with shorter sensory blocking times and less motor blocking. Adverse effects, including hypotension, bradycardia, pruritus, chills, nausea, and vomiting, did not differ between the two groups.

\section{Competing interests}

The authors declare that they have no competing interests.

\section{Authors' contributions}

\begin{tabular}{|l|c|c|c|}
\hline Authors' contributions & QTN & NHH & NVC \\
\hline Research concept and design & $\sqrt{ }$ & -- & -- \\
\hline Collection and/or assembly of data & $\sqrt{ }$ & -- & -- \\
\hline Data analysis and interpretation & -- & $\sqrt{ }$ & $\sqrt{ }$ \\
\hline Writing the article & -- & $\sqrt{ }$ & -- \\
\hline Critical revision of the article & -- & $\sqrt{ }$ & $\sqrt{ }$ \\
\hline Final approval of article & -- & $\sqrt{ }$ & $\sqrt{ }$ \\
\hline Statistical analysis & $\sqrt{ }$ & $\sqrt{ }$ & -- \\
\hline
\end{tabular}


Nguyen et al. Journal of Anesthesiology \& Clinical Science 2021, http://www.hoajonline.com/journals/pdf/2049-9752-10-1.pdf

\section{Acknowledgment}

We would like to thank all the patients who participated in this study.

Publication history

EIC: D. John Doyle, Case Western Reserve University, USA.

Received: 27-April-2021 Final Revised: 11-May-2021

Accepted: 25-May-2021 Published: 12-Jun-2021

\section{References}

1. W. Mebust, "Transurethral surgery," Campbell's Urology, vol. 2912, 1992.

2. W. Mebust, H. Holtgrewe, A. Cockett, P. Peters, and W. Committee, "Transurethral prostatectomy: immediate and postoperative complications. A cooperative study of 13 participating institutions evaluating 3,885 patients," The Journal of urology, vol. 167, no. 2 Part 2, pp. 999-1003, 2002.

3. T. N. Sinh, "Indicated endoscopic ablation in obstruction of the lower urinary tract due to benign prostate tumors," PhD, Ho Chi Minh University of Medicine and Pharmacy, Ho Chi Minh University of Medicine and Pharmacy, 2001.

4. S. Atabekoğlu and F. Bozkırlı, "Comparison of the clinical effects of intrathecal ropivacaine and bupivacaine in geriatric patients undergoing transurethral resection," Gazi Medical Journal, vol. 18, no. 4, 2007.

5. S. Leone, S. Di Cianni, A. Casati, and G. Fanelli, "Pharmacology, toxicology, and clinical use of new long acting local anesthetics, ropivacaine and levobupivacaine," Acta Biomed, vol. 79, no. 2, pp. 92-105, 2008.

6. E. Erturk, C. Tutuncu, A. Eroglu, and M. Gokben, "Clinical comparison of $12 \mathrm{mg}$ ropivacaine and $8 \mathrm{mg}$ bupivacaine, both with $20 \mu \mathrm{g}$ fentanyl, in spinal anaesthesia for major orthopaedic surgery in geriatric patients," Medical Principles and Practice, vol. 19, no. 2, pp. 142-147, 2010.

7. S. A. Sheta, E. A. Eid, and A. A. Moussa, "Spinal Ropivacaine in fast-track TURP," AJAIC, vol. 8, no. 2, 2005.

8. L. Critchley, "Hypotension, subarachnoid block and the elderly patient," Anaesthesia, vol. 51, no. 12, pp. 1139-1143, 1996.

9. B. J. Ganvit, P. H. Patel, and H. R. Ahir, "Comparison of Intrathecal Ropivacaine with Fentanyl and Bupivacaine with Fentanyl for Urological Surgery," group, vol. 2, no. 12, 2013.

10. V. Kölükçü, T. Karaman, S. Karaman, S. Doğru, H. Tapar, and M. Süren, "The Effect of General and Spinal Anaesthesia on Pulmonary Function Tests in Geriatric Patients," Istanbul Medical Journal, vol. 21, no. 6, 2020.

11. M. C. Dsouza, R. Fernandez, and S. Selvam, "A STUDY TO DETERMINE THE EFFECTS OF INTRATHECAL FENTANYL COMBINED WITH 0.5\% BUPIVACAINE (HYPERBARIC) FOR SUBARACHNOID BLOCK ON THE DURATION AND QUALITY OF POST-OPERATIVE ANALGESIA," Journal of Evolution of Medical and Dental Sciences, vol. 7, no. 51, pp. 6211-6216, 2018.

12. N. H. Hoa, N. V. Chinh, and T. Yang, "Relationship between Facemask Ventilation and Post Operating Nausea and Vomiting in Vietnam," IOSR Journal of Nursing and health Science, vol. 10, no. 2, pp. 54-59, 2021.

\section{Citation:}

Nguyen QT, Hoa NH and Chinh NV. Comparison of intrathecal ropivacaine-fentanyl and bupivacainefentanyl in transurethral resection of the prostate of the benign prostatic hyperplasia surgeries. J Anesthesiol Clin Sci. 2021; 10:1. http://dx.doi.org/10.7243/2049-9752-10-1 